\title{
La supresión sería la única medida capaz de evitar la saturación del sistema de salud por COVID-19
}

\author{
The suppression would be the only measure capable of avoiding the saturation of the health system by COVID-19
}

\section{Comentado de:}

Ferguson NM, et al. Imperial College COVID-19 Response Team $2020^{1}$

\section{Objetivos}

En ausencia de una vacuna para COVID-19, evaluar los potenciales resultados de una serie de medidas globales (intervenciones no farmacológicas: INF) de mitigación y/o supresión a nivel de la salud pública, sobre la demanda al sistema de salud y la mortalidad por esta enfermedad.

\section{Diseño}

Modelo de simulación individual (MSI), desarrollado para apoyar la planificación de la influenza pandémica y así explorar diversos escenarios de COVID-19 en el Reino Unido (RU) y los Estados Unidos (EE.UU.). Se mantuvo la estructura básica de ese modelo sin considerar implicancias éticas ni económicas.

\section{Asunciones del modelo}

La población se distribuyó de manera individual en el modelo de simulación de acuerdo a los datos disponibles sobre densidad poblacional, distribución estructural de los hogares, tamaño promedio de los cursos escolares y características de los distintos lugares de trabajo.

Según datos recabados por los autores, se asumieron los siguientes parámetros: 1) periodo de incubación de 5,1 días; 2) contagiosidad a partir de las 12 horas previas al inicio de los síntomas y luego de 4,6 días de la infección en personas asintomáticas; 3) R0 (Número promedio de casos secundarios generados por un caso índice infeccioso en una población susceptible) $=2,4$ $(2,0$ a 2,6$) ; 4)$ los contactos plausibles de generar contagio entre un individuo infeccioso y otro susceptible pueden ocurrir en hoga- res, escuelas, lugares de trabajo y en la comunidad en general; 5) tasa de mortalidad global por infección (TMI) ajustada por edad de $0,9 \%$; 6) $30 \%$ de los hospitalizados requerirá cuidados críticos (UCl) y $50 \%$ de estos morirá; 7) duración promedio de la hospitalización de 10,4 días.

\section{Intervención}

Los autores consideraron el impacto de cinco diferentes INF (ver Tabla 1) implementadas individualmente y en forma combinada, entendiendo de esta manera que estas se pueden aplicar de dos maneras:

1. Supresión: pretende reducir el número reproductivo básico (R0) por debajo de 1 y, por lo tanto, reducir el número de casos a niveles bajos y/o eliminar la transmisión de persona a persona. El principal desafío de esta estrategia es que las INF necesitan ser mantenidas mientras exista circulación viral humana o hasta que una vacuna esté disponible.

2. Mitigación: pretende reducir el impacto de la pandemia en el sistema de salud (no interrumpir por completo la propagación viral), al reducir el R0 pero sin lograr que éste descienda por debajo de 1.

La Tabla 1 describe las asunciones de las principales medidas que podrían ser adoptadas para mitigar o suprimir la transmisión de COVID-19 y la estimación de la proporción de su cumplimiento.

Fueron explorados cuatro escenarios con diferentes estrategias: a) ausencia de medidas de control, b) mitigación, c) supresión, d) políticas adaptativas que asocian estrategias de mitigación y supresión.

Tabla 1. Asunciones de las principales medidas que podrían ser adoptadas para mitigar o suprimir la transmisión de COVID-19 y estimación de la proporción de su cumplimiento. Nota: NR: no reportado.

\begin{tabular}{|c|c|c|}
\hline Intervenciones & Descripción & $\begin{array}{l}\text { Cumplimiento } \\
(\%)\end{array}$ \\
\hline $\begin{array}{l}\text { Aislamiento domici- } \\
\text { liario de los casos }\end{array}$ & $\begin{array}{l}\text { Los casos sintomáticos deben permanecer en casa durante siete días, lo que reduciría los contactos no } \\
\text { domésticos el } 75 \% \text {, sin repercusión en los contactos domésticos. }\end{array}$ & 70 \\
\hline $\begin{array}{l}\text { Aislamiento domici- } \\
\text { liario de los contactos }\end{array}$ & $\begin{array}{l}\text { Tras la identificación de un caso que presente síntomas dentro de la familia, todos los miembros permane- } \\
\text { cen en casa durante } 14 \text { días. El grado de contacto con los familiares se duplica durante este período de } \\
\text { cuarentena y el contacto con la comunidad se reduce } 75 \% \text {. }\end{array}$ & 50 \\
\hline $\begin{array}{l}\text { Distanciamiento } \\
\text { social de los mayores } \\
\text { de } 70 \text { años }\end{array}$ & $\begin{array}{l}\text { Se reduce } 50 \% \text { el contacto en los lugares de trabajo, aumenta el contacto con los miembros de la familia } \\
\text { el } 25 \% \text { y se reduce el resto de los contactos el } 75 \% \text {. }\end{array}$ & 75 \\
\hline $\begin{array}{l}\text { Distanciamiento } \\
\text { social general }\end{array}$ & $\begin{array}{l}\text { Todas las familias reducen el contacto fuera de casa el } 75 \% \text {. El grado de contacto en las escuelas no } \\
\text { cambia, mientras que el grado de contacto en los lugares de trabajo se reduce } 25 \% \text {. Se asume que el } \\
\text { grado de contacto con los familiares aumenta } 25 \% \text {. }\end{array}$ & $\mathrm{NR}$ \\
\hline $\begin{array}{l}\text { Cierre de escuelas y } \\
\text { universidades }\end{array}$ & $\begin{array}{l}\text { Se cierran todas las escuelas, y el } 25 \% \text { de las universidades permanecen abiertas. El grado de contacto } \\
\text { con los familiares del estudiante dentro del hogar aumenta } 25 \% \text { durante este período. El contacto con la } \\
\text { comunidad aumenta } 25 \% \text { durante el cierre. }\end{array}$ & NR \\
\hline
\end{tabular}




\section{Resultados principales}

El modelo estimó que sin la toma de medidas, la pandemia podría provocar entre mayo y junio de 2020 más dos millones de muertes en EE.UU. y cerca de medio millón en el RU.

Ls estrategia más efectiva de mitigación sería la combinación de aislamiento de los casos y de los contactos, y un distanciamiento social de los mayores de 70 años (ver Tabla 2), mientras que dentro de las estrategias de supresión, el distanciamiento social a nivel poblacional, en combinación con el aislamiento domiciliario de casos y contactos, y en asociación con el cierre de escuelas tiene el potencial de suprimir la transmisión por debajo del límite $R 0=1$, requerido para reducir rápidamente la incidencia de casos (ver Tabla 3).

Tabla 2. Impacto relativo (porcentaje de reducción) de diferentes intervenciones, aplicadas en una eventual estrategia de mitigación en el Reino Unido durante tres meses, sobre la mortalidad y la demanda máxima de camas en las unidades de cuidados intensivos. Notas: $\mathrm{R} 0=2,4$; Las medidas se activarían a nivel nacional cuando la incidencia de casos semanales de COVID-19 en unidades de cuidados intensivos sobrepasen el límite establecido de 300 camas ocupadas.

\begin{tabular}{|l|c|c|c|}
\hline Desenlaces & $\begin{array}{c}\text { Cierre de } \\
\text { escuelas y } \\
\text { universida- } \\
\text { des }\end{array}$ & $\begin{array}{c}\text { Aislamiento } \\
\text { de casos }\end{array}$ & $\begin{array}{c}\text { Aislamiento de } \\
\text { casos } \\
\text { y contactos y } \\
\text { distanciamiento } \\
\text { social de mayores } \\
70 \text { años }\end{array}$ \\
\hline $\begin{array}{l}\text { Demanda máxima } \\
\text { de camas en UCl }\end{array}$ & $\downarrow 14 \%$ & $\downarrow 33 \%$ & $\downarrow 67 \%$ \\
\hline Muertes totales & $\downarrow 2 \%$ & $\downarrow 17 \%$ & $\downarrow 49 \%$ \\
\hline
\end{tabular}

Tabla 3. Impacto estimado de la estrategia de supresión en el Reino Unido en comparación con la "no intervención" en la estimación del número total de muertes y pico de ocupación de camas en unidades de cuidados intensivos durante un periodo de dos años de simulación. Nota: $R 0=2,4$; Las medidas se activarían a nivel nacional cuando la incidencia de casos semanales de COVID-19 en unidades de cuidados intensivos sobrepasen el límite establecido de 300 camas ocupadas.

\begin{tabular}{|l|c|c|}
\hline Desenlaces & $\begin{array}{c}\text { No aplicar } \\
\text { ninguna } \\
\text { estrategia }\end{array}$ & $\begin{array}{c}\text { Aislamiento de casos y } \\
\text { contactos + cierre de } \\
\text { escuelas y universidades + } \\
\text { distanciamiento social } \\
\text { general }\end{array}$ \\
\hline $\begin{array}{l}\text { Demanda máxima } \\
\text { de camas en UCl }\end{array}$ & 180.000 & 4.000 \\
\hline Muertes totales & 510.000 & 34.000 \\
\hline
\end{tabular}

\section{Conclusiones}

La efectividad de cualquier INF aislada puede ser limitada, por lo que se requiere la combinación múltiples intervenciones para lograr un impacto significativo en la transmisión de COVID-19. La aplicación de una estrategia de mitigación parece una opción poco viable si es que se pretende que la capacidad de atención de los sistemas de salud no se vea sobrepasada en los países estudiados, por lo que la estrategia de supresión sería la más adecuada.

Fuente de financiamiento/Conflicto de interés de los autores: Centro por el Consejo de Investigaciones Médicas del RU, Departamento de Desarrollo Internacional del RU, Unidad de Investigación de Protección de la Salud en la Metodología de Modelación del NIHR y Fundación Abdul Latif Jameel. No se reportaron conflictos de interés.

\section{Comentario}

La exploración de la efectividad de diferentes medidas para contener, mitigar o suprimir los contagios por SARS-CoV-2 es un tema de altísimo interés público y sujeto a acalorados debates.

Los modelos de simulación individual (MSI) utilizados para lograr este objetivo, ayudan a generar proyecciones y diseñar estrategias de control de procesos dinámicos que están sujetos a la estocástica y a la heterogeneidad, como las enfermedades infecciosas. Estos modelos recrean situaciones en un entorno computacional basándose en las características y las interacciones de los diferentes actores sociales que pueden modelarse a tal efecto ${ }^{2}$. Sin embargo, sus proyecciones deben utilizarse con suma cautela, dado que su calidad depende de la información obtenida de la vigilancia epidemiológica, que como se sabe -y especialmente en contextos de pandemia-, es altamente imperfecta.

Por otro lado, los MSI con los que contamos todavía no han podido incorporar en forma satisfactoria aspectos económicos y sociales, de gran importancia a la hora de implementar toda política de mitigación o supresión de este tipo pandemia. Por ese motivo, destacamos que sus resultados constituyen una herramienta más que puede ser de ayuda a las autoridades sanitarias, aunque que las decisiones gubernamentales no pueden basarse pura y exclusivamente en este tipo de estimaciones matemáticas.

Por último, si bien los resultados del equipo del Imperial College pueden parecer algo sombríos, son consistentes con otros estudios de modelado desarrollados hasta el momento, que informan un beneficio claro de las medidas de cuarentena simuladas; que se asociarían con mejores resultados en términos de incidencia y mortalidad cuando se combinan con otras medidas como el cierre de las escuelas, la restricción de viajes y el distanciamiento social ${ }^{3}$.

\section{Conclusiones del comentador}

Más allá de las limitaciones de los MSI, pareciera que por el momento y ante la ausencia de una vacuna, no hay alternativas mucho mejores a la estrategia de supresión, si es que se desea evitar que los sistemas de cuidados de la salud se saturen y colapsen. Mientras tanto, debemos tomar todas las medidas que sean necesarias con precaución, procurando no provocar daños de peores consecuencias que lo que estamos tratando de evitar y comprendiendo que nuestro conocimiento sobre sus potenciales consecuencias está basado en supuestos. 
Mauricio P Kemnitz [ Servicio de Medicina Familiar y Comunitaria, Hospital Italiano de Buenos Aires. mauricio.kemnitz@hospitalitaliano.org.ar ]

Kemnitz M. La supresión sería la única medida capaz de evitar la saturación del sistema de salud por COVID-19. Evid Actual Pract Ambul. 2020;23(3):e002084. Comentado de: Ferguson NM, et al. Report 9: Impact of non-pharmaceutical interventions (NPIs) to reduce COVID-19 mortality and healthcare demand. Imperial College COVID-19 Response Team 2020

\section{Referencias}

1. Ferguson NM, Laydon D, Nedjati-Gilani G, et al.. Report 9: Impact of non-pharmaceutical interventions (NPIs) to reduce COVID-19 mortality and healthcare demand; 2020. Available from: https://www.imperial.ac.uk/media/imperial-college/medicine/sph/ide/gida-fellowships/Imperial-CollegeCOVID19-NPI-modelling-16-03-2020.pdf [Last access: 2020-07-27].

2. Nepomuceno EN, Resende DF, Lacerda MJ. A Survey of the Individual-Based Model applied in Biomedical and Epidemiology Research. J Biomed Res Rev. 2018;1(1):11-24. Available from: 10.3619/2581-7388.1000102.

3. Nussbaumer-Streit B, Mayr V, Dobrescu AI, et al. Quarantine alone or in combination with other public health measures to control COVID-19: a rapid review. Cochrane Database Syst Rev. 2020;4(4):CD013574. Available from: 10.1002/14651858.CD013574. 